\title{
RESEÑA: PALABRAS EXTREMAS: ESCRITORAS GALLEGAS E IRLANDESAS DE HOY. MANUELA PALACIOS GONZÁLEZ Y HELENA GONZÁLEZ FERNÁNDEZ (EDS.) ${ }^{1}$
}

\author{
María Bobadilla Pérez ${ }^{2}$
}

\begin{abstract}
Palacios González, M. y H. González Fernández (Eds.) 2008: Palabras extremas: Escritoras gallegas e irlandesas de hoy. A Coruña: Netbiblo. 159 páginas. ISBN: 97884-9745-198-7.
\end{abstract}

El presente estudio, Palabras extremas: Escritoras gallegas e irlandesas de hoy está dirigido a especialistas en el campo de los estudios de género y de la literatura comparada. También a quienes basen su investigación en la búsqueda de aspectos comunes reflejados en dos tradiciones literarias, la gallega y la irlandesa, cuyos contextos históricos y sociales se han desarrollado paralelamente. Este estudio está enmarcado en la colección "Amergin Irish Studies Series", dirigida por Antonio Raúl de Toro Santos (Editorial Netbiblo) y dedicada a explorar las diferentes aportaciones culturales del ámbito irlandés, con un enfoque dirigido al estudio de las relaciones de éste con España en general, y Galicia en particular. Dentro de esta serie podemos encontrar otros títulos como Ireland in the Coming of Time o Postcolonial and Gender Perspectives en los que también ha colaborado la profesora Palacios González, profesora titular de Filología Inglesa en la Universidad de Santiago de Compostela y co-editora del volumen que reseñamos junto con Helena González Fernández, profesora titular de literatura gallega en la Universidad de Barcelona. En este volumen las profesoras Palacios y González proponen una discusión de posiciones teóricas anteriores para analizar el discurso literario, los estudios feministas y de género, y nos proponen en esta colaboración una lograda comparación del escenario actual en el que se desarrolla la escritura lírica femenina contemporánea.

En esta línea, este estudio incide sobre aspectos comunes que han definido la producción poética del siglo XX en Galicia y en Irlanda, para revelar el papel que desempeñan sus autoras tanto en las formaciones discursivas de su sociedad y de su nación, como en el desarrollo de una consciencia femenina que trascienda las barreras nacionales. Tanto para Irlanda como para Galicia, las editoras de este volumen señalan la relevancia de la década de los 70 en la transformación de ambas sociedades. Si en España comienza el proceso de transición tras la dictadura franquista, la sociedad irlandesa también vive una etapa de agitación marcada por un periodo de trágica violencia. Así mismo, las editoras afirman que esta década está definida por la lucha por las libertades y por los derechos de las mujeres

Fecha de recepción: septiembre 2009.

Fecha de aceptación y versión definitiva: septiembre 2009.

2 Profesora Tutora, Departamento de Filología Inglesa, UNED; $₫$ mariabobad@hotmail.com. 
en el ámbito internacional, acontecimientos que tendrán un impacto determinante en la producción poética de las autoras del último cuarto del siglo XX.

Este estudio, tal y como afirman las autoras, no sólo contribuye a difundir la obra de poetas irlandesas y gallegas contemporáneas y el destacado papel que éstas han tenido en la definición del "oxímoron identitario sexo-género/nación” (xxiii), sino que además aproxima estudios críticos y manifestaciones de creación literaria para crear un espacio dialógico. Con este fin, las autoras aciertan a estructurar el volumen en dos partes complementarias: una primera en la que se abordan estudios críticos comparativos sobre la obra de las poetas gallegas e irlandesas, y una segunda en la que se le cede la palabra a las propias protagonistas a través de ensayos o entrevistas para que puedan expresar de primera mano sus propuestas e inquietudes.

La primera parte se presenta articulada en tres bloques temáticos que son esenciales para la creación de un espacio identitario y discursivo de la subjetividad femenina, y a los que las poetas gallegas e irlandesas recurren frecuentemente en su representaciones: naturaleza, lenguaje y mito. Los dos primeros capítulos de esta parte analizan el papel de la naturaleza en la voces poéticas femeninas gallegas e irlandesas. Por una parte, María Xesús Nogueria Pereira estudia la función del paisaje gallego en la construcción de esa identidad. Si en el siglo XIX Rosalía de Castro inaugura la integración del paisaje dentro del discurso poético gallego, habrá que esperar hasta la posguerra para encontrarlo en la obra poética del siglo $\mathrm{XX}$, y hasta el último tercio del siglo para que esta integración se consolide. En la voz de poetas como Chus Pato, Ana Romaní, o Mariña Pérez Rey, el imaginario paisajístico está ligado a la construcción de la identidad. En este sentido, en su poesía se plasmarán tanto las tensiones entre el mundo rural y el urbano - que servirán como metáfora de la inestabilidad del sujeto lírico- como una mirada ecocrítica a través de la cual manifestarán su conciencia ecológica. Siguiendo esta línea, y a modo de comparación con las poetas gallegas, el segundo capítulo de este bloque profundiza en la configuración del espacio natural desde una perspectiva ecofeminista. Manuela Palacios analiza la obra de las poetas irlandesas actuales y halla en ellas una conciencia generacional en torno a las inquietudes ecologistas que tendrán como resultado importantes cambios en la percepción y representación del entorno rural. En consecuencia, se manifestará en su obra una reacción contra las tradicionales “apropiaciones ideológicas que identifican tierra, mujer y nación.”(26)

El segundo bloque se centra en el papel de la lengua y el lenguaje en la construcción de la identidad. Siguiendo la estructura paralela del primer bloque, Helena González y Laura Lojo estudian en sendos capítulos el tratamiento de estos conceptos en la poesía gallega e irlandesa. Por una parte, Helena González comienza presentando una visión filológica y sociológica de la tradicional relación entre los conceptos de lengua y nación. En este sentido, analiza cómo se reflejan las diferencias generacionales en el uso de la lengua gallega en la poesía femenina desde la transición. Si para la generación de Xela Arias o Chus Pato "el gallego es un territorio elegido, marcado por la militancia" (32), las poetas más jóvenes eligen una lengua u otra ya con cierta normalidad, y utilizan el lenguaje como "laboratorio" no sólo poético sino también identitario. En el cuarto capítulo, "Corporeidad y lenguaje en la poesía irlandesa actual", Laura Lojo analiza la obra de autoras como Eavan Boland o Anne Hartigan a partir de las teorías feministas de Hélène Cixious o Julia Kristeva, quienes articulan la adecuación del lenguaje a la experiencia femenina. En este sentido, a 
través de un proceso de re-escritura se cuestionan en la obra de estas poetas la significación tradicional de los conceptos de subjetividad y feminidad, para así presentar "un escenario poético nuevo el que las mujeres reposen su cuerpo y su voz" (62).

Esta primera parte crítica se completa con dos capítulos que giran en torno a una revisión mítica, tan presente en el marco teórico feminista. María Xesús Lama, en el quinto capítulo, analiza los mitos en la poesía gallega actual. En ésta, los mitos tradicionales, en su mayoría de tradición judeocristiana, grecolatina o céltica, son revisados o reinterpretados bien para establecer un diálogo con la tradición, o incluso para cuestionarlos como respuesta a una actitud crítica hacia la realidad. La presencia del mito en la lírica femenina irlandesa actual es el objeto de estudio del último capítulo de esta sección. Luz Mar González Arias analiza con acierto los efectos que han tenido las transformaciones sociales sobre la voces poéticas femeninas que recurren a "Penélopes, Medusas, Casandras y Filomenas" (93) para articular una historia diferente, a pesar de que hayan podido encontrar más dificultades que sus coetáneas gallegas en la re-escritura de esos mitos.

En la segunda parte de este volumen se les cede la palabra a las propias poetas quienes en sus ensayos críticos y entrevistas profundizan en las condiciones culturales en las que desarrollan su labor creativa. En el primer capítulo de esta sección, la poeta María do Cebreiro reflexiona sobre cuál es la función de la poesía de mujeres y sobre la relación entre la poesía y el cuerpo y su significado político en la poesía gallega escrita por mujeres. El siguiente capítulo es un ensayo de la escritora irlandesa Ann Le Marquand Hartigan en el que, al igual que la poeta gallega, reflexiona sobre el porqué de la escritura. Marquand Hartigan se plantea del porqué de la escritura femenina en la época actual a través de una reflexión sobre la relación entre la construcción de la identidad y los cambios culturales "que ponen freno al potencial creativo de las mujeres" (xxvii) o sobre la sensación de no expresarse la lengua propia. Estas reflexiones, plasmadas en una combinación bellísima de poesía y ensayo, llevarán a la autora a reconocer que el propio "acto de escribir se convierte por sí mismo en un acto de reconciliación" (124) entre aquello que ellas desean expresar y la incapacidad de hacerlo tan bien como deserían.

El libro concluye con dos capítulos que transcriben las entrevistas con poetas gallegas e irlandesas. Así, en el capítulo noveno, María Xesús Nogueira Pereira entrevista a dos de las poetas representativas del panorama gallego, Chus Pato y Ana Romaní. María Xesús Nogueira propone una lectura cruzada de las dos entrevistas a través de la cual podremos profundizar en sus propuestas estéticas. Se plantean en las mismas debates sobre el papel que Rosalía de Castro tuvo en la construcción del sujeto lírico femenino gallego, sobre la revisión de la tradicional relación entre mujer y nación, o sobre las estrategias empleadas en la construcción del discurso o de la identidad. Las autoras proponen diferentes aproximaciones en sus propuestas estéticas, no obstante se pueden apreciar lugares comunes y afinidades en la construcción identitaria del sujeto femenino o en la revisión del discurso. En el último capítulo del libro, Luz Mar González Arias entrevista a las dos escritoras Irlandesas Mary O'Donnel y Celia de Fréine. En la primera entrevista con Mary O'Donnel se plantean cuestiones tales como la elección del gaélico como medio creativo, la temática recurrente en su obra o la existencia de una tradición de literatura femenina en Irlanda. En la entrevista con Celia de Fréine se debate sobre el uso de la lengua y las implicaciones de escoger la lengua gaélica como medio creativo, como son la falta de visibilidad o cierta 
marginalidad dentro de los discursos académicos. Tampoco se pasan por alto en esta entrevista los enormes cambios sociales que se han dado en Irlanda en la última década y la influencia que éstos han tenido sobre la literatura irlandesa, y en particular sobre la poesía escrita por mujeres.

Las profesoras Palacios González y González Fernández contribuyen con este estudio al impulso de los estudios comparativos entre dos culturas históricamente hermanadas, Galicia e Irlanda. La estructura del libro se plantea como una serie de capítulos en los que aparentemente los temas irlandeses y los gallegos se desarrollan de manera paralela, pero cuyos caminos confluyen en la respuesta reflexiva del lector tras la lectura global del libro. A pesar de las diferencias culturales y contextuales de cada nación se reconocen claramente esas señas de identidad que hacen del sujeto lírico femenino una entidad transnacional. Palabras Extremas: Escritoras gallegas e irlandesas de ayer y de hoy se presenta como una cuidada selección de ensayos y entrevistas coherentes y ambiciosas, que tienen como resultado un estudio de gran interés para aquellos que deseen profundizar en los estudios de literatura comparada, de género e identidad y en las relaciones culturales entre Galicia e Irlanda. 